\title{
Preservice School Counselors' Math Anxiety and Worst Math Experiences
}

\author{
Gurpal K. Gill and Cass Dykeman ${ }^{1}$ \\ Oregon State University \\ 104 Furman Hall \\ Corvallis, OR 97331-3502
}

A Preprint

\begin{abstract}
Almost two decades have passed since Jackson and Leffingwell's (1999) influential article on math anxiety and worst math experiences in preservice school teachers appeared in print. No studies examining these issues with school counselors exist. The present study represents a partial replication of the original study with 70 preservice school counselors. The participants were graduate-level preservice counselors at a public university on the west coast of the US. The six research questions that guided the study aimed to assess differences between the present study and (a) the original study, and (e) a Turkish replication of the original study. No statistically significant results were obtained comparing the original and present study. However, significant differences between the present study and the Turkish replication were encountered. Possible reasons for the obtained results were discussed along with the implications.
\end{abstract}

Keywords: mathematics anxiety, preservice counselors, most troublesome experiences, worst experiences

\footnotetext{
${ }^{1}$ Correspondence concerning this article should be addressed to Gurpal Gill at gillgu@onid.orst.edu
} 


\section{Preservice School Counselors' Math Anxiety and Worst Experiences as Students in Math Classes}

School counselors are often the go-to person when students are trying to sort their educational interests. They play a vital role in directing the path that many students will take in their academic pursuits. Many school counselors are known for their expertise in researching and discovering possible skill sets that students hope to establish, which makes school counselors versatile experts in a multitude of possibilities and careers. Possessing knowledge in a number of areas is significant for students who in their attempts to figure out what the best path for their academic development and endeavors would be. School counselors hold a pivotal role in this exploration, making them knowledgeable in language arts, the sciences, math, and the arts. But what happens when school counselors neglect exploration in content areas that make them uncomfortable to bring up negative experiences in their learning? Can counselors still be effective in directing students to explore a number of academic possibilities, or would the counselors' narratives taint the possibility of exploration for students in academic areas they may be intimated to explore?

Since the National Defense Education Act of 1958, school counselors have been tasked with directing talented students toward collegiate studies in math and science. This task continues today through the national emphasis on STEM education. However, no literature exists on possible barriers to school counselors who engage in this task. For instance, what percentage of school counselors have significant math anxiety and/or had negative experiences as students in math classes that might adversely affect their ability to perform STEM guidance?

The focus of this study is to discover the degree to which school counselors have significant math anxiety and/or had negative experiences as students. For this study, four topics covered in the literature will be reviewed: (a) the traumatic math experiences of school counselors, (b) the traumatic math experiences of school counselors as related to their math anxiety, (c) the behaviors associated with counselors who experience math anxiety, (d) the effects of such behaviors on the populations for which they provide counseling services and support. Finally, the specific research questions will be detailed. 
Given the limited research on counselors' specific math experiences, it is pertinent to address that this limitation is an area of concern, and that the research benefits will be endless to such a profession and the populations served when considering the number of students who are impacted by counseling services every day. Math anxiety is prevalent among preservice teachers. Such knowledge also opens doors to recognize that many preservice counselors work in schools; they may have been former teachers and will encounter student experiences as they struggle and plan their education related to their career choices. In other words, the discussion of math performance is bound to take place. If preservice counselors have had traumatic math experiences or are math anxious, these outcomes can certainly impact the quality of counseling services they will provide to the populations they serve.

Schmidt, Hardinge, and Rakutani (2012) stated that "Given their varied professional responsibilities, counselors may miss the significance of their role in establishing one of the earliest anticipatory expectations with regard to how a student views his or her ability in specific academic areas" (p. 27). A counselor's role is significant because counselors can open or close doors for students who have an interest in a multitude of subjects such as math. Schmidt et al. noted, "Some authors (Gibbons \& Borders, 2010; National Office for School Counselor Advocacy [NOSCA], 2010) have maintained that school counselors serve as gatekeepers of student potential" (p. 26).

School counselors as gatekeepers can help students explore possible academic paths, or they can discourage them. Much discussion has centered on STEM careers, which are heavily rooted in math. "The World Economic Forum (2010) ranked the United States 48th in the quality of math and science education. The 2010 ACT College Readiness report indicated that $76 \%$ of high school graduates did not meet high school benchmarks for readiness in one or more freshman-level courses" (American College Testing, 2010, p. 1). To respond to this emerging crisis effectively and thrive within an evolving technological society, "All students need to develop their capabilities in science, technology, engineering, and math (STEM) to levels much beyond what was considered acceptable in the past" (Schmidt, Hardinge, \& Rakutani, 2012, p. 25). Knowing this information, it is 
imperative for school counselors to address the needs of their student population and also assist in increasing STEM interest. However, what happens if school counselors have their own anxieties around math performance, and they hinder discussions in the academic areas in which they have limited success or interest? Counselor limitations become important because these professionals can either increase student interest in math careers or deter students from pursuing these fields due to their own anxiety and fear of math.

Jackson and Leffingwell (1999) researched the traumatic experiences of preservice teachers in their math classes. These experiences were outlined as the following: hostile instructor behavior, unrealistic expectations, embarrassing students in front of peers, gender bias, and insensitive and uncaring attitudes of teachers. Bekdemir (2010) also studied preservice teachers' math experiences and found that these teachers had both worst and most troublesome math experiences. Given these experiences of preservice teachers, could they also be the experience of other professionals such as preservice counselors? If they are, then researching them becomes significant.

These math experiences also connote behaviors and implications that become significant for performance outcomes. For example, Bekdemir's research (2010) discussed the implications for preservice teachers and teaching. Jackson and Leffingwell (1999) described the experiences that preservice teachers encountered as both overt and covert behaviors that produced anxiety during their math education. As research is conducted, it may be safe to conclude that such experiences could also impact preservice counselors in a similar manner with implications regarding how they counsel and affect students in the realm of math anxiety. Math anxiety and negative classroom experiences have been shown to impact instructional practices. For instance, Lazarus (1974) stated, "One obstacle to the prevention of mathophobia is the difficulty of early diagnosis ... the educational system inadvertently promotes mathophobia" (p. 19). Moreover, Fiore (1999) wrote, "Evidence suggests that math anxiety results more from the way the subject matter is presented than from the subject matter itself" (p. 403). Boyd, Foster, Smith, and Boyd (2014) reported on the teacher-to-student transmission of math anxiety. The authors posited that "Preservice teachers and math are centered on math anxiety, and if not 
addressed in the teacher, (the anxiety) is thought to be transferred from the teacher to student with immediate and long-term educational implications" (p. 208). Boyd et al. recognized that the prevalence of math anxiety in preservice teachers has a negative impact on both their own self-efficacy and that of the students they teach. Their research suggested that this awareness be generated and discussed among preservice elementary teachers to aid in diminishing such effects on students through seeking a mentor while teaching. Gresham (2008) studied the impact of preservice elementary teachers' effectiveness, their instructional effectiveness, and their potential of passing on the math anxiety to their students. Gresham's research found that focusing on traditional instructional practices increases the likelihood of math anxiety in students when compared to nontraditional instructional practices. If preservice teachers were aware of this problem, they would find a greater possibility of reducing math anxiety within themselves and employing instructional practices that (a) increase selfefficacy in students and (b) reduce the transference of math anxiety. This information is significant for preservice counselors, who have a major role in helping students process coursework, course selection, and career selection related to math.

School counselors have a pivotal role in guiding and advising students in STEM occupations. Based on American School Counselor Association (ASCA) standards and National Standards for School Counseling Programs, much emphasis is placed on career assistance and guidance. Feller (2011) outlined these expectations as a standard of practice for school counselors: "Beyond helping students (1) acquire the skills to investigate the world of work in relation to knowledge of self and to make informed career decisions, (2) employ strategies to achieve future career goals with success and satisfaction, and (3) understand the relationship between qualities, education training, and the world of work (Dahir, 2001, p. 324), becoming a STEM advocate is gaining traction among school counselors" (p. 16). In fact, school counselors can encourage and assist all students, including underprivileged populations, to enter STEM careers that are in high demand and increase the United States' competiveness in science and technology (Feller, 2011). STEM occupations have a strong component of math competence. If counselors are math anxious, the possibility that they will be limited in their efforts to guide students in STEM careers is real. The limited research on counselors' 
specific math experiences is an area of concern. Math anxiety is prevalent among preservice teachers. Having such knowledge opens doors to recognize that many preservice counselors work in schools, may have been former teachers, and will encounter students who struggle in planning their education as it relates to their career choices. In other words, the discussion of math performance is unavoidably bound to take place, which places this responsibility within the purview of school counselors. If preservice counselors have had traumatic math experiences or are math anxious, these outcomes can certainly impact the quality of counseling services they provide to the populations they serve.

The literature has suggested that students are not ready to engage in STEM education. Given that school counselors assist and guide students in the areas of class selection and career and college planning, these counselors can be considered as the gatekeepers of careers. This pivotal role affects how they advise students to plan for their futures and increase their interests to explore STEM curriculum and careers. Some of this impact and significance can be found in Schmidt et al.'s (2012) research, which stated, "It is important that school counselors do not overlook their professional obligation to provide rigorous, well-rounded, exploratory, and relevant opportunities for students; career development trajectories" (p. 27). School counselors play a vital role in assisting students in their learning and career process. When they demonstrate a lack in this area, the implications are seen throughout the United States. The World Economic Forum (2010) ranked the United States $48^{\text {th }}$ in the quality of math and science education. The 2010 ACT College Readiness report indicated that $76 \%$ of high school graduates did not meet high school benchmarks for readiness in one or more freshman-level courses (American College Testing, 2010). To respond effectively to this emerging crisis and thrive within an evolving technological society, "All students need to develop their capacities in science technology, engineering, and math (STEM) to levels much beyond what was considered acceptable in the past" (Schmidt et al., 2010, p. 625).

School counselors' vital role guides students' learning and opens up their possibilities in STEM education and careers. They can open or close doors for students who have an interest in a multitude of subjects such as math. Research that Schmidt et al. (2011) conducted stated, "Given their varied professional responsibilities, counselors may miss the significance of 
their role in establishing one of the earliest anticipatory expectations with regard to how a student views his or her ability in specific academic areas" (p. 27). Schmidt et al. reported, "Some authors (Gibbons \& Borders 2010, National Office for School Counselors Advocacy [NOSCA], 2010) have maintained that school counselors serve as gatekeepers of student potential" (p. 26). The school counselor's role in guiding, planning, and introducing students to varied opportunities in learning that they may have missed, not considered, or are too scared to explore, such as the STEM curriculum, can begin with the counselor's knowledge and training and how he or she direct students to challenge their learning.

The following six research questions guided this study:

1. What is the level of mathematics anxiety among preservice counselors?

2. How many preservice counselors reported having a worst experience?

3. Does the preservice counselor participants' level of math anxiety differ from a known college student norm?

4. Does the proportion of preservice counselors who reported a worst math experience differ from a known proportion among American educators?

5. Does the proportion of preservice counselors who reported a worst math experience differ from a known proportion among Turkish educators?

6. Do the proportions of when preservice counselors reported a worst math experience occurring differ from known proportions among Turkish educators?

7.

\section{Method}

\section{Design}

Design and variables specifics. This study employed a cross-sectional observational design (Jepsen, Johnsen, Gillman, \& Sørensen, 2004). The study involved the use of a convenience sample of preservice school counselors. Issues involved with using such a sample will be addressed later in this article. Three variables were observed in the present study: (a) math anxiety (continuous variable), (b) whether counselors had a worst experience in a math class during their own time as a student (binomial 
variable), and (c) the grade level at which they had that worst experience (multi-categorical variable).

Power analyses. The third through sixth research questions involved inferential statistics. As such, a priori power analysis for each research question was completed by means of $\mathrm{G}^{*}$ Power (Faul, Erdfelder, Buchner, \& Lang, 2009). With the third research question, the power analysis used was for a one-sample $t$-test. The proper effect size for a $t$-test is Cohen's $d$ (Rosnow \& Rosenthal, 2003). The effect size was drawn from a math anxiety study of college students (Primi, Busdraghi, Tomasetto, Morsanyi, \& Chiesi, 2014). The power analysis was completed using these inputs: (a) Test family $=t$-tests; (b) Statistical tests $=$ means: difference from a constant (one sample case); (c) Type of power analysis = a priori: compute required sample size - given $\alpha$, power, and effect size; (d) tail(s) $=2 ;(\mathrm{e}) d$ $=-0.69$; (f) power $(1-\beta$ error probability $)=0.80$; and $(\mathrm{g}) \alpha=.05$. The $\mathrm{G}^{*}$ Power 3.1 output included a total sample size of 19 and an actual power of 0.81 .

The fourth and fifth research questions included frequency counts. The results formed a two-cell table of frequency counts (Cell $1=$ No; Cell 2 $=$ Yes). Thus, the power analysis was for a binomial test. The proper effect size for this power analysis is Cohen's $g$ (Rosnow \& Rosenthal, 2003).

For the fourth research question, the proportion observed was drawn from what appears on page 583 of Jackson and Leffingwell (1999). Specifically, $p$ observed was .93 (146/157). Therefore, Cohen's $g$ was .43 ( $p$ observed -.50$)$. The following input parameters were employed: (a) test family = exact; (b) statistical test $=$ proportions: difference from constant (binomial test, one sample case); (c) the type of power analysis = a priori: compute required sample size given $\alpha$, power, and the effect size; (d) tail(s) $=2,(\mathrm{e}) g=0.43 ;$ (f) power $(1-\beta$ error probability $)=0.8 ;(\mathrm{g}) \alpha=.05$; and $(\mathrm{h})$ constant proportion $=.50$. The $\mathrm{G}^{*}$ Power output suggested a sample size of 9 and an actual power of .87 .

For the fifth research question, the proportion observed was drawn from the Worst Experience data presented in Table 2 of Bekdemir (2010). Specifically, $p_{\text {observed was }} .77$ (129/167). Therefore, Cohen's $g$ was .27 ( $p_{\text {observed }}$ -.50). The following input parameters were employed: (a) Test family = 
exact; (b) Statistical test = proportions: difference from constant (binomial test, one sample case); (c) the type of power analysis = a priori: compute required sample size given $\alpha$, power, and the effect size; $(\mathrm{d})$ tail $(\mathrm{s})=2$, (e) $g=0.27$; (f) power $(1-\beta$ error probability) $=0.8 ;(\mathrm{g}) \alpha=.05$; and $(\mathrm{h})$ constant proportion $=.50$. The $\mathrm{G}^{*}$ Power output suggested a sample size of 25 and an actual power of .80 .

For the sixth research question, results were compared against expected proportions drawn from Table 5 of Bekdemir (2010). As such, a power analysis was for a chi-square goodness-of-fit test. The proper effect size for such a test is Cohen's w (Rosnow \& Rosenthal, 2003). The effect size was drawn from a study examining the interaction of learning and addiction variables in an educational setting (Huepe et al., 2011). The input parameters were: (a) Test family- $\chi 2$ tests, (b) Statistical testGoodness-of-fit tests: contingency tables, (c) Type of power analysis- a priori: compute required sample size- given $\alpha$, power, and effect size, $(d) W$ $=0.42$, (e) power $(1-\beta$ error probability) $=0.80$, (f) $\alpha=.05$, and $(\mathrm{g})$ degrees of freedom $(D f)=2$. The $\mathrm{G}^{*}$ Power 3.1 output suggested a sample size of 55 with an actual power of 0.80 .

In summary, the required sample size ranged from 9 (fourth research question) to 55 (sixth research question). As such and given the number of participants in the present study, no analysis will be underpowered.

\section{Participants}

This study involved 70 preservice counselors located at one public university and a satellite campus for the same university in the western United States. The participants were predominantly female (81\%) and male $(19 \%)$. The mean age was 32.50. $(S D=7.697)$. The majority of the sample size was composed of Caucasian students equaling 80\%. Students of color represented $20 \%$ of the sample, Hispanic/Latino $=0.029 \%$, African American $=0.014 \%$, Asian American $=0.043 \%$ ), American Indian/Alaska Native represented $=0 \%$, and multiple races $/$ ethnicities $=0.100 \%$.

\section{Measures}


Abbreviated Math Anxiety Scale (AMAS). The AMAS is a brief, nine-item measure of math anxiety with strong psychometric properties including internal consistency $(\alpha=.90)$ and test-retest reliability $(\mathrm{r}=.85)$ (Hopko et al., 2003). The AMAS is widely used in math anxiety research across multiple cultures (Eden, Heine, \& Jacobs, 2013; Primi et al., 2014; Tejedor et al., 2009). On this measure, participants are asked to rate each of the nine items on a five-point Likert scale with $1=$ Low Anxiety to $5=$ High Anxiety. The range of scores is 9 to 45 . Primi et al. found a $\mathrm{M}=21.6$ (SD $=6.3$ ) in using the AMAS with college students. In their studies using the AMAS with college students, Hopko, Hunt, and Armento (2005) and Hopko, Crittendon, Grant, and Wilson (2005) reported means of 21.8 (SD = $5.2)$ and $21.5(\mathrm{SD}=5.5)$, respectively. Maloney, Risko, Ansari, and Fugelsang (2010) used the following cut scores for the AMAS with college students: (a) Low Anxiety $\leq 19$, and (b) High Anxiety $\geq 30$. As per Maloney et al., the following coding scheme was used for the analysis: Low Anxiety $(\leq 19)=1$, Moderate Anxiety $(20-29)=2$, and High Anxiety $(\geq$ $30)=3$. Dykeman (2017) studied the AMAS average across 17 studies involving college students. He reported that the weighted average for the 17 studies $(\mathrm{N}=6439)$ was 22.66 . This weighted average served as the test value for the third research question.

\section{Worst Experience and Most Troublesome Mathematics Classroom} Experience Reflection Test (WMTMCERT) -Presence. This questionnaire involves the participants answering open-ended questions describing the "worst" experiences in a math classroom (Bekdemir, 2010; Jackson \& Leffingwell, 1999). Consistent with Bekdemir, as well as Jackson and Leffingwell, "worst" was defined to the participants as a negative and anxiety-creating student experience. The following dummy coding scheme was used for the analysis: no report of a worst experience $=1$, a report of one or more worst experiences $=2$, and missing $=-99$. The reference proportions for the fourth research question (Americans, Jackson \& Leffingwell, 1999) was $p_{0}=.93$ (146/157), and the fifth research question (Turkish, Bekdemir, 2010) was $p_{0}=.77(129 / 167)$.

\section{Worst Experience and Most Troublesome Mathematics Classroom} Experience Reflection Test (WMTMCERT) -Timing. Participants were also asked to report in "what grade (K through 12) did this worst experience occur?" The grades reported were then recoded in the grade 
categories that Bekdemir (2010) used: (a) Grades 1-5 = 1, (b) Grades 6-8 = 2, (c) Grades 9-11 = 3, (d) Grades 12-14=4, and (e) missing $=-99$. The reference proportions from the Turkish preservice teachers can be found in Table 1 of Bekdemir (2010).

\section{Procedures}

A questionnaire containing the WMTMCERT, AMAS, and demographic questions was administered to preservice counselors. These questionnaires in a pencil and paper format were administered in an introductory pedagogy class. A printing company created both the demographic questions and the AMAS in an optical mark recognition form (i.e., Scantron) so that data could be easily compiled and organized.

\section{Data Analysis}

For the first research question, determining the prevalence level involved a calculation of a mean, standard deviation, and skewness. The second research question called for determining frequency counts and percentages. The third research question involved comparing the results of a continuous variable against a national norm. As such, one-sample $t$-test was applied to the analysis. The fourth and fifth research questions compared an obtained proportion against a known proportion. In this case, a one-sample $z$ test for a proportion was the analysis used. The sixth and final research question involved comparing a multi-categorical variable against a known norm for those categories. Thus, a chi-square goodness-offit test was employed. Missing data were addressed using listwise deletion. For all analyses, calculations were completed using Excel, and the alpha level was set at .05.

\section{Results}

The first research question sought to determine the level of math anxiety among preservice counselors. The level of math anxiety that the participants reported on the AMAS was $21.83(S D=7.93$, skewness = .38). With respect to the second research question, the number of participants who reported that they had a worst experience was $88 \%$ (i.e., $61 / 69)$. In the matter of the third research question, a comparison of the obtained AMAS scores against a known college student norm did not 
produce significant results, $t(68)=-.87, p>.05$. In terms of the fourth research question (i.e., compare to an American sample), a one-sample $z$ test for proportion did not yield a significant result $\left(\hat{p}=.88, p_{0}=.93, n=69, z\right.$ $=-1.493, p>.05$ ). With regard to the fifth research question (i.e., compare to a Turkish sample), a one-sample $z$ test for proportion did yield a significant result ( $\left.\hat{p}=.88, p_{0}=.77, n=69, z=2.211, p<.05\right)$. In reference to the sixth research question, a frequency count of when preservice counselors reported a worst math experience occurred and can be found in Table 1. The grade category proportions differed significantly from those reported from a Turkish sample, $\chi 2(3, N=61)=10.16, p<.05$.

\section{Discussion}

The six research questions of this study examined the levels and relationships of the following in preservice counselors: (a) math anxiety, and (b) presence of worst experience in a math classroom. The results will be discussed research question by question.

In terms of the first research question (measures of central tendency), the observed mean of math anxiety scores fell slightly over the mid-point of the potential mathematical range of scores (i.e., $36 / 2=18$ ). The skew kurtosis indicated a roughly symmetrical distribution of scores with light tails. Such results are most likely a product of the fact that the participants were drawn from a homogenous group (i.e., same professional program and grade level from one school).

In reference to the second research question (how many preservice counselors reported a worst experience), $88 \%$ of the preservice counselors reported having had a worst experience. When compared to a survey sample of American educators, the sample results were the same. A sample size of 69 American preservice counselors demonstrated an $88 \%$ result of worst experience; results indicated that 61/69 American preservice counselors demonstrated math anxiety. One explanation for this finding is that counselors have a high existing base rate of math anxiety. Jackson and Leffingwell's (1999) research showed that out of 157 sampled students, only 11 students reported having positive math experiences. 
An alternative explanation is that the prevalence of a base rate of math anxiety has been established; therefore, it can be concluded that preservice counselors will have a high rate of math anxiety. Jackson and Leffingwell (1999) established that the majority of students certified to teach, who were sampled in their research, had math anxiety. It can be concluded that this high rate will exist among preservice counselors. A 2011 National Survey of School Counselors, Counseling at a Crossroads, found that $73 \%$ of school counselors had a $58 \%$ chance of being teachers or administrators prior to becoming counselors. If a high base rate of math anxiety exists, then it has been established that preservice counselors will have a worst experience.

The most plausible reason is that counselors have a high base rate of math anxiety. The base rate norm for this group is high; therefore, it is expected that the prevalence of math anxiety is present in this population, which will thus ensure that this population will have a worst math experience.

With regard to the third research question (math anxiety level compared to a known college norm), the participants did not differ from a known norm of college students. One possible reason for this result is that in terms of math anxiety, those drawn into counseling as a profession do not differ from college students as a whole. Supporting this conclusion is the fact that the third most popular major in the US is Social Sciences and History, and the fourth is Psychology (National Center for Educational Statistics, 2017). An alternative explanation is the convenience nature sampling in math anxiety research with college students. Most math anxiety researchers are psychologists, and perhaps the research in this field is overweighted with psychology majors. Thus, the nondifference encountered in this study just reflects this overweighting. Between these two explanations, the most probable is the former, given: (a) the breadth of research on college students with various majors (Hembree, 1990), and (b) the known differences in college majors with those in the social sciences (including psychology) having higher levels of math anxiety (Hembree, 1990; Schillinger, Vogel, Diedrich, \& Grabner, 2018).

The fourth research question was, "Does the proportion of preservice counselors reporting a worst math experience differ from a known 
proportion among American Educators?" There is no difference between American educators and preservice counselors who had a worst math experience. American educators demonstrated similar math anxiety results to a known proportion of preservice counselors, which was $88 \%$ of preservice counselors who reported having a worst math experience. This finding was almost similar to what the college norm reported, which was $93 \%$. The American educators reported a slightly higher percentage of worst experience than preservice counselors. A reason for this difference might be that math anxiety exists regardless of the country. In other words, it is a universal experience in various countries and in a multitude of populations.

An alternative explanation might be that preservice counselors have certain personality types that are prone to having math anxiety prior to becoming preservice counselors. Based on Hadfield and McNeil's (1994) research, one of the suggested origins of math anxiety was personality ( $p$. 3). These authors also found that people who had an extroversion trait had scored lower on math anxiety in comparison to their opposite counterparts. Hadfield and McNeil also found that certain personality types are attracted to the elementary school teaching profession, and in these personalities, there is a higher prevalence of math anxiety.

The same authors also found that people with the personality type of "feeling" were attracted to the school counseling profession, and these populations have a higher tendency to be math anxious. Hadfield and McNeil (1994) proposed a possible solution: employing math specialists to teach mathematics to teachers who are highly math anxious. These teachers are more "feeling" types, and this personality type has more math anxiety. They are not analytical, but they have traits that young children need in the academic environment. This research demonstrated that certain personality types are drawn to elementary school teaching while having higher levels of math anxiety.

The most plausible explanation is that math anxiety exists in many populations regardless of the country or place of origin. Bekdemir's (2010) research found that most Turkish students reported having math anxiety throughout their academics. Kalaycioglu's (2015) research found the highest mean level of math anxiety in Turkey based on the five countries researched. The research further stated that this math anxiety might be 
explained by different educational systems in the countries researched. The study also discussed that countries such as Hong Kong, Turkey, and Greece utilize high-stakes testing to allocate which academic high schools students will attend. These countries also use high-stakes testing to determine which middle schools that students will attend.

With regard to the fifth research question (American v. Turkish proportion of worst math experiences), one of the reasons the proportions of American preservice counselors and Turkish educators might vary is due to American preservice counselors' need to take higher levels of math courses later on in their academic career in comparison to Turkish educators. Turkish educators engage in high-stakes testing, but those in the US do not. Kalaycığlu's (2015) article stated, "Math anxiety levels may be explained by the different educational systems in these countries. Educational systems of developing countries such as those of Turkey, Greece, and Hong Kong are more centralized and more challenging for students. These countries' education systems currently use high-stakes testing as a means of allocating students into academic high schools, and students are ranked depending on their test scores" (p. 1399). The US does not engage in highstakes testing, which might explain the reason for higher proportions of math anxiety in the Turkish populations at younger grade levels. However, in the US, math anxiety may surface in the later academic years when a career choice is necessary, and math becomes a focal point for achieving that career.

Another possible explanation is that the junior colleges in the US are places where students can recover some of the academic functioning and career exploration skills if they did not do so in high school. In Turkey, students have to pick a path at younger ages while performing towards that goal, or they lose the opportunity for college completion. Students in Turkey usually begin to focus on technical programs to build task skills for employment because academic options are no longer open to them due to their performance and the established academic rules in Turkey's educational system. In the US, students can redeem their splintered academic skills long after they graduate from high school by attending junior college. The proportion of worst math experiences mostly likely happens at higher rates at the junior college and at the 4-year college level 
because math becomes significant for academic and degree success, as well as career planning. The research of Jackson and Laanan (2015) found that nearly half of the students who attend community college do so to complete preparation for STEM careers. In addition, the research of Floyd, Haley, Eddy, and Antczak (2009) shared that community colleges are an access point for students for higher learning as well as job training. When considering such a need in the US, it is important to recognize that other countries do not have community college access. Thus, math anxiety is more prevalent in earlier years when compared to a US population of students who can continue to work towards their career goals by attending community colleges and requesting transfer agreements.

In terms of the sixth research question (timing of worst math experie nce), three possible reasons could explain the results obtained. The first possible reason is that high-stakes testing of math performance occurs earlier in the Turkish educational system when compared to the US educational system. Kalaycığlu (2015) noted the following:

Educational systems of developing countries such as those of Turkey, Greece, and Hong Kong, are more centralized and more challenging for students. These countries' education systems currently use high-stakes testing as a means of allocating students into academic high schools, and students are ranked depending on their test scores. In Hong Kong, Turkey, and Greece, students are allowed access to specific schools based on their exam score starting in middle school. (p. 1399)

Preparation of students in Turkey begins much sooner to be competitive for academic institutions. In countries like Turkey, high-stakes testing preparation begins in the primary years of education for students, and performance on these tests will determine if students will have access to competitive high schools. It is also important to note that high-stakes performance in a country like Turkey determines a student's college opportunities and future success.

The second reason could be that the pay and retention consequences for poor student performance in math occur earlier for Turkish teachers. An other reason could be that hiring consequences and retention for poor 
student performance in math occur earlier for Turkish teachers. The research of Kılınç, Watt, and Richardson (2012) stated that considerable attention is focused on selecting math and science teachers. Kılınç et al. also stated; "In accordance with the modernization of Turkey, there is aggressive attention to the quality, especially in scientific/mathematical domains ... There is consonant high attention to the quality of mathematics/science teachers, as indicated by higher requisite entry scores to undertake teacher education in those specialties" (p. 200). It can be concluded that the rigor in teacher selection and expectation begins well before a teacher is hired to teach science and math. If teachers are committed to the requirements to become math teachers, the same expectations are most likely required of their students to prepare to enter high-achieving institutions.

A third reason relates to parent expectation. Perhaps Turkish parents press for greater math performance at earlier ages than American parents. For example, the literature has reported that it is not uncommon for Turkish parents to hire tutors to improve their child's performance in elementary school years (Atalmis, Yilmaz, \& Saatcioglu, 2016). In the Turkish culture, extra rigor goes into selecting math and science teachers, and parents also know that preparation is a joint effort between these teachers and parents to ensure college entry for their children.

Kılınç, et al.'s (2012) research stated, "As early as grade 9 (the first year of secondary education), students are required to select science versus social science strands for their remaining education" (p. 200). Parent involvement begins at a young age due to the rigor of performance expectations.

Among these three reasons, the most probable explanation for the results obtained is the first one because Turkish students, based upon test scores, are tracked into college and non-college pathways far earlier than American students. Atalmis, Yilmaz, and Saatcioglu (2016) stated:

Entrance exams for both high school and university are highly competitive in the Turkish educational system. The first step of this competition for Turkish students is the high school entrance exam administered by the Ministry of National Education once a year. Students 
are supposed to take this exam in the last year of primary education (8th grade), and they are accepted to prestigious high schools only if they obtain high scores on the test. (p. 1136) Given that high-stakes testing begins in middle school and determines college access, it would be the strongest driver as to the timing of a worst math experience.

\section{Limitations}

When considering the results of this study, three limitations should be kept in mind. First, this study used a cross-sectional design. A known limitation with this design relevant to this study is that it is used to gather data on a specific population in a given time period. Second, the study used a convenience sample. Convenience samples cannot be used globally to generalize an outcome for additional populations. They can only be used to draw conclusions about the population that was sampled. A third limitation involved the narrow demographic profile of the sample. The limited diversity of the sample surveyed was composed of one university with multiple campuses on the west coast of the US, and the population was predominantly Caucasian. Although this researcher sampled multiple campuses of one region on the west coast of the US, they were primarily Caucasian. A more diverse sample might yield different results.

\section{Implications}

The implications for counselors' preparation research are fourfold. First, no researchstudy has explored the impact that school counselors have on students, and yet school counselors have a pivotal role in assisting students with class selection, career exploration, and collegerequirements. Given the high percentage rate of school counselors who were previously teachersalso indicates the prevalence of high math anxiety in many American preservice teachers, who also reported having a worst math experience. With limited research and the inability to answer why this is happening, effective interventions are limited for teachers, thus with similar limitations for preservice counselors. In addition, no research has been conducted to answer why preservice teachers' experience math anxiety can also apply to school counselors, thus limiting effective treatment strategies or knowing when the intervention strategies areneeded the most. This deficit perpetuates a math-stagnant and limited student population. 
The second implication relates to the timing of the worst experience. The data collected recognized that math anxiety increases in later years for preservice counselors. These data are significant because counselors may have a perception that math anxiety is common through lateryears due to their own experiences. Thus, they dismiss the needs of the younger students they counsel, who might be expressing their concerns with math anxiety. This anxiety might be normalized versus school counselors who assist students with effective therapeutic treatment for anxiety. In other words, school counselors might be limited by their narrow views and performance when it comes to math.

Third, if math anxiety is elevated in student populations, school counselors might compare data and state that the math anxiety is a norm, which leads to poor performance in STEM careers in the US, versus looking for possible solutions for boosting math performance.

Fourth, school counselors may not consider increasing math performance by reducing math anxiety as a needed intervention, or they may not seek further training in the area because they have dismissed the need or are limited to few, if any, interventions. This lack of awareness that the problem could be remedied exists because the research is scarce, thus enabling and perpetuating a cycle of helplessness. 


\section{References}

Atalmis, E. H., Yilmaz, M., \& Saatcioglu, A. (2016). How does private tutoring mediate the effects of socioeconomic status on mathematics performance? Evidence from Turkey, Policy Futures in Education, 14, 1135-1152. doi: 10.1177/1478210316674159

Bekdemir, M. (2010). The preservice teachers' mathematics anxiety related to depth of negative experiences in mathematics classroom while they were students. Educational Studies in Mathematics, 75, 311-328. doi:10.1007/s10649-010-9260-7

Boyd, W., Foster, A., Smith, J., \& Boyd, W. E. (2014). Feeling good about teaching mathematics: Addressing anxiety among preservice teachers. Creative Education, 5, 207-217. doi.org/10.4236/ce.2014.54030

Bridgeland, John, \& Bruce, Mary. (2011). National survey of school counselors: Counseling at a Crossroads. College Board Advocacy \& Policy Center.

Dunn, R., Honigsfled, A., Doolan, L. S., Bostrom, L., Russo, K., Schiering, M., Marjorie, S., Suh, B., \& Tenedero, H. Impact of learning-style instructional strategies on students' achievement and attitudes: Perceptions of educators in diverse institutions. The Clearing House, 82, 135-141.

Dykeman, C. (2017). The weighted average of Abbreviated Math Anxiety Scale (AMAS) studies on college students. Corvallis, OR: Oregon State University. doi:10.13140/RG.2.2.13827.50721

Faul, F., Erdfelder, E., Buchner, A., \& Lang, A.-G. (2009). Statistical power analyses using $\mathrm{G}^{*}$ Power 3.1: Tests for correlation and regression analyses. Behavior Research Methods, 41, 1149-1160. doi:10.3758/BRM.41.4.1149

Feller, R. (2011). Advancing the STEM workforce through stem-centric career development: As ITEEA members prepare students for the success skills needed within a "skills bias" workplace, taking a STEM-centric view can prove helpful. Technology and Engineer Teacher, 71, 6-12.

Fiore, G. (1999). Math-abused students: Are we prepared to teach them? The National Council of Teachers, 92, 403-406. Retrieved from http://www.jstor.org/stable/27971020 
Floyd, D. L., Haley, A., Eddy, P. L., \& Antczak, L. (2009). Celebrating the past, creating the future: 50 years of community college research. Community College Journal of Research and Practice, 33, 216-237.

Green, C. L., Walker, J. M. T., Hoover-Dempsey, K. V., \& Sandler, H. M. (2007). Parents' motivations for involvement in children's education: An empirical test of a theoretical model of parental involvement. Journal of Educational Psychology, 99, 532-544.

http://dx.doi.org/10.1037/0022-0663.99.3.532

Gresham, G. (2008). Mathematics anxiety and mathematics teacher efficacy in elementary pre-service teachers. Teaching Education, 19, 171-184. https://doi.org/10.1080/10476210802250133

Hadfield, O. D., \& Mcneil, K. (1994). Learning styles of elementary preservice teachers. The Clearing House, 75, 142-145.

Kılınç, A., Watt, H. G., \& Richardson, P. (2012). Factors influencing teaching choice in Turkey. Asia-Pacific Journal of Teacher Education, 40, 199-226. doi: 10.1080/1359866X.2012.700048

Hembree, R. (1990). The nature, effects, and relief of mathematics anxiety. Journal for Research in Mathematics, 21(1), 33-46. doi:10.2307/749455

Hopko, D., Crittendon, J., Grant, E., \& Wilson, S. (2005). The impact on performance IQ. Anxiety, Stress, and Coping, 18, 17-35. doi: $10.1080 / 10615800412336436$

Hopke, D., Hunt, M. K., \& Armento, M. (2005). Attentional task aptitude and performance anxiety. International Journal of Stress Management, 12, 389-408. doi: 10.1037/1072-5245.12.4.389

Hopko, D. R., Mahadevan, R., Bare, R. L., \& Hunt, M. K. (2003). The abbreviated math anxiety scale (AMAS): Construction, validity, and reliability. Assessment, 10, 187-182. http://dx.doi.org/10.1177/1073191103252351

Howard, S. K. (2013). Risk-aversion: Understanding teachers' resistance to technology integration. Technology, Pedagogy, and Education, 22, 357-372. http://dx.doi.org/10.1080/1475939X.2013.802995

Huepe, D., Roca, M., Salas, N., Canales-Johnson, A., Rivera-Rei, Á. A., Zamorano, L., \& Ibañez, A. (2011). Fluid intelligence and psychosocial outcome: From logical problem solving to social adaptation. PLoS One, 6, e24858. https://doi.org/10.1371/journal.pone.0024858 
Jackson, C. D., \& Leffingwell, R. J. (1999). The role of instructors in creating math anxiety in students from kindergarten through college. The Mathematics Teacher, 92, 583-586. Retrieved from http://www.jstor.org/stable/27971118

Jackson, D. L., \& Laanan, F. S. (2015). Desiring to fit: Fostering the success of community college transfer students in STEM. Community College Journal of Research and Practice, 39, 132-149. https://doi.org/10.1080/10668920802614512

Jepsen, P., Johnsen, S. P., Gillman, M. W., \& Sørensen, H. T. (2004). Interpretation of observational studies. Heart, 90, 956-960. http://dx.doi.org/10.1136/hrt.2003.017269

Kalaycioğlu, B. D. (2015). The influence of socioeconomic status, selfefficacy, and anxiety on mathematics achievement in England, Greece, Hong Kong, the Netherlands, Turkey, and the USA. Educational Sciences: Theory and Practice, 15, 1391-1401. doi: $10.12738 /$ estp.2015.5.2731

Lazarus, M. (1974). Mathophobia: Some personal speculations. National Elementary Principal, 53, 16-22.

Maloney, E. A., Risko, E. F., Ansari, D., \& Fugelsang, J. (2010). Mathematics anxiety affects counting but not subitizing during visual enumeration. Cognition, 114, 293-297. http://dx.doi.org/10.1016/j.cognition.2009.09.013

Morris, J. (1981). Math anxiety: Teaching to avoid it. National Council of Teachers of Mathematics, 74, 413-417.

Primi, C., Busdraghi, C., Tomsaetto, C., Morsanyi, K., \& Chiesi, F. (2014). Measuring math anxiety in Italian college and high school students: Validity, reliability, and gender invariance of the Abbreviated Math Anxiety Scale (AMAS). Learning and Individual Differences, 34, 51-56. http://dx.doi.org/10.1016/j.lindif.2014.05.012

Rosnow, R. L., \& Rosenthal, R. D. (2003). Effects sizes for experimenting psychologist. Canadian Journal of Experimental Psychology, 63, 221237. doi: 10.1037/h0087427

Schillinger, F. L., Vogel, S. F., Diedrich, J., \& Grabner, R. (2018). Math anxiety, intelligence, and performance in mathematics: Insights from the German adaptation of the Abbreviated Math Anxiety Scale (AMAS-G). Learning and Individual Differences, 61, 3-7.

Schmidt, C., Hardinge, G., \& Rakutani, L. (2012). Expanding the school counselor repertoire through STEM-focused career development. The 
Career Development Quarterly, 60, 25-35.

https://doi.org/10.1002/j.2161-0045.2012.00003.x

Young, C., Wu, S., \& Menon, V. (2012). The neurodevelopmental basis of math anxiety. Psychological Science, 23, 492-501. doi:

10.1177/0956797611429134 
Table 1

Grade Level of Worst Experience

\begin{tabular}{ccccc}
\hline Data & \multicolumn{3}{c}{ Grade } \\
& $1-5$ & $\begin{array}{c}\text { Levels } \\
6-8\end{array}$ & $9-11$ & $12-14$ \\
\hline $\begin{array}{c}\text { Observed Frequency-US } \\
\text { Observed Proportion- }\end{array}$ & 7 & 6 & 28 & 20 \\
$\begin{array}{c}\text { US } \\
\text { Expected Proportion* }\end{array}$ & .11 & .10 & .46 & .33 \\
Absolute Difference & $|.07|$ & .23 & .34 & .25 \\
\hline
\end{tabular}

*Calculated from Turkish data reported by Bekdemir (2010). 